\title{
Norwegian Priority Setting in Practice - an Analysis of Waiting Time Patterns Across Medical Disciplines
}

\author{
Jurgita Januleviciute Gangstøe ${ }^{1}$, Torhild Heggestad ${ }^{2}$, Ole Frithjof Norheim ${ }^{2 *}$
}

\begin{abstract}
Background: Different strategies for addressing the challenge of prioritizing elective patients efficiently and fairly have been introduced in Norway. In the time period studied, there were three possible outcomes for elective patients that had been through the process of priority setting: (i) high priority with assigned individual maximum waiting time; (ii) low priority without a maximum waiting time; and (iii) refusal (not in need for specialized services). We study variation in priority status and waiting time of the first two groups across different medical disciplines. Methods: Data was extracted from the Norwegian Patient Register (NPR) and contains information on elective referrals to 41 hospitals in the Western Norway Regional Health Authority in 2010. The hospital practice across different specialties was measured by patient priority status and waiting times. The distributions of assigned maximum waiting times and the actual ones were analyzed using standard Kernel density estimation. The perspective of the planning process was studied by measuring the time interval between the actual start of healthcare and the maximum waiting time.

Results: Considerable variation was found across medical specialties concerning proportion of priority patients and their maximum waiting times. The degree of differentiation in terms of maximum waiting times also varied by medical discipline. We found that the actual waiting time was very close to the assigned maximum waiting time. Furthermore, there was no clear correspondence between the actual waiting time for patients and their priority status.

Conclusion: Variations across medical disciplines are often interpreted as differences in clinical judgment and capacity. Alternatively they primarily reflect differences in patient characteristics, patient case-mix, as well as capacity. One hypothesis for further research is that the introduction of maximum waiting times may have contributed to push the actual waiting time towards the maximum. The finding that the actual waiting time was very close to the maximum waiting time supports this. The lack of clear correspondence between the actual waiting time for patients and their priority status may imply that urgency, described in the referral letter, and severity of illness, according to guidelines, are two separate entities.

Keywords: Waiting Lists, Prioritization, Healthcare Sector

Copyright: (c) 2016 by Kerman University of Medical Sciences

Citation: Gangstøe JJ, Heggestad T, Norheim OF. Norwegian priority setting in practice - an analysis of waiting time patterns across medical disciplines. Int J Health Policy Manag. 2016;5(6):373-378. doi:10.15171/ijhpm.2016.23
\end{abstract}

\section{Article History:}

Received: 30 June 2015

Accepted: 22 February 2016

ePublished: 2 March 2016

\section{Key Messages}

\section{Implications for policy makers}

- This study found that most of the patients received healthcare within maximum waiting times, but many patients received treatment just before this assigned maximum time. Policy-makers may consider ways to change the management of waiting lists.

- Low-priority patient groups sometimes wait shorter than high-priority groups. This could be explained by variation in capacity and differences in clinical judgments. This calls for revision of the guidance documents and better harmonization across medical disciplines.

Implications for the public

This study looked at how patients' right to healthcare services and maximum waiting times have been translated into practice in Norway. We found that a large majority of the patients received healthcare within maximum waiting times, but that there are variations between types of services. Such variations are to be expected because diseases, and patients, are different and their severity of illness varies. However, some of these differences in access to care may be unacceptable and could be explained by variation in capacity and differences in clinic judgments. These types of variations should be reduced.

\section{Introduction}

Fair allocation of healthcare services is a general aim, but also a great challenge for all healthcare systems. Universal healthcare systems typically provide access to high quality care and financial risk protection, but are also known for generating waiting lists. ${ }^{1}$ Reducing waiting time for elective procedures is a continuous health policy issue in many OECD (Organisation for Economic Co-operation and Development) countries. $^{2}$ Several mechanisms have been introduced including maximum waiting time guarantees (The United Kingdom, the Netherlands, Finland, Sweden, Denmark, Norway), often linked to economic incentives (see for example ${ }^{3}$ ). Other countries introduced additional mechanisms of patient choice and increased reliance on private providers. Some countries also developed prioritization tools ensuring that patients with higher urgency or severity are treated more 
quickly. Examples of such tools are severity scoring systems (New Zealand and Canada), or discipline-specific guidance with individual maximum waiting times (Norway).

The first official report addressing principles for priority setting in Norway was developed in 1987 (later revised in 1997 and 2014). ${ }^{4}$ The system was differentiated further by introducing a set of waiting time guarantees. ${ }^{5}$ These guarantees were replaced by the Patients Rights Act of 1999. 6,7 According to this Act, $\$ 2-1$, the patient has a right to specialized healthcare if three criteria are met: (1) the patient has a condition which affects prognosis related to life expectancy or quality of life if healthcare is delayed, (2) the patient has expected utility of the healthcare, and (3) there is a reasonable relation between the costs and effectiveness of the service.

The Patients Rights Act further specifies that each elective patient must be considered individually and if assigned a right, also given a specific maximum waiting time. From 2004, this individual maximum waiting time was combined with a new incentive mechanism. If this maximum waiting time is exceeded, the patient has a legal right to file a complaint and choose treatment at another hospital at the cost of the initial health enterprise. This cost is proportional to the expected cost of treatment. Complaints are rarely filed. In addition, patients have free choice among public providers, and a right to appeal on the priority assigned by the hospital.

Preliminary data from the Norwegian Patient Register (NPR) indicated that the assignment of rights and maximum waiting times were practiced differently among the health regions. ${ }^{8}$ The share of patients qualifying for the right to necessary healthcare varied from $48 \%$ to $69 \%$ in different health regions in $2010 .^{9}$ It was postulated that patients received different status and different maximum waiting times depending on where they lived and which hospital they were referred to. Experience from a pilot study in the Western Health Region also indicated different prioritization practices among different specialties. ${ }^{10}$

The issue of waiting lists has been given high political attention, and in 2007 the Ministry of Health and Care Services, therefore, commissioned the Regional Health Authorities and the Norwegian Medical Association to develop guidance documents for more than 30 different specialties. These guidance documents for how to set priorities should be distinguished from clinical practice guidelines that are developed through a different process with different methods for assessment and appraisal. This guidance was meant to standardize prioritization practice in the country and to provide advice on which patient groups should be assigned a right to specialized healthcare and their maximum waiting times. ${ }^{7,11}$ These guidance documents were developed and implemented in 2009.12 Table 1 provides two examples of guidance for hip arthrosis and severe to moderate depression. Thus the Norwegian priority-setting policy for elective specialized services includes (i) The Patient's Rights Act of 1999 (revised in 2004 and 2013); (ii) A governmental white paper on priority setting; and (iii) National priority-setting guidance documents for more than 30 medical disciplines. In the time period of interest (year 2010), there were three possible outcomes for elective patients that had been through the process of priority setting: (i) high priority with assigned individual maximum waiting time; (ii) low priority without a maximum waiting time; (iii) refusal (not in need for specialized services).

Little is so far known about how this guidance affected the actual priority setting across different specialties. It is, therefore, interesting to examine waiting time patterns for elective patients in a period after the introduction of the guidance documents. This baseline can then be used to evaluate further changes in waiting time regulations that are proposed but not yet fully implemented.

The aim of this article was to study variation in priority status and waiting times across different medical disciplines for elective patients admitted in 2010 to specialized services within one Regional Health Authority in Norway. More specifically, we explored three questions: (i) Were the prioritization profiles similar for different specialties? (ii) When were the services provided, compared to assigned maximum waiting time? (iii) What was the relation between priority status and actual waiting time?

\section{Methods}

Waiting lists and the priority given to hospital patients can be closely monitored by patient administrative data. These hospital data are collected locally and transferred to the national level into the NPR. To analyze the prioritization practice at the hospitals located in the Western Regional Health Trust, data was selected from the national register. The population in the region is about 1 mill. Our dataset contains detailed information on patients with at least one planned hospital contact during the year 2010. The number of hospitals included was 41 and the total number of remissions was 388112 .

We used three different outcome measures to describe how the hospitals prioritize patients in practice: (1) the proportion of prioritized patients (assigned a legal right to necessary healthcare); (2) the assigned individual maximum waiting time for prioritized patients; and (3) the actual waiting time independent of priority group.

Waiting time is defined as the interval from the referral is received at the hospital until access to healthcare. However, this does not always mean start of treatment since physicians might need additional information to fully assess the referral and before treatment can be started. The maximum waiting time is defined from the same reference point until the date of the individually assigned maximum waiting time. We excluded some referrals from the analyses according to the operationalization used in official waiting list statistics (like cases where a first appointment was postponed by a patient, or appointments for follow-up), as well as cases where waiting time or assigned maximum waiting time exceed two years (this amounts to $2 \%$ and $1 \%$ of the dataset, respectively).

To analyze the distributions of actual waiting times and assigned maximum waiting times, standard kernel density (Epanechnikov) estimation was used. Kernel density estimate $\mathrm{f}(\mathrm{x})$ where $\mathrm{x}=x_{0}$, is, $\hat{f}\left(x_{0}\right)=\frac{1}{N h} \sum_{i=1}^{N} K\left(\frac{x_{i}-x_{0}}{h}\right)$ where $\mathrm{h}$ is the smoothness parameter and $K$ is the Kernel function that assigns more weight to the $\mathrm{x}$-values that are closer to $x_{0}{ }^{13}$ The calculations for mean, standard deviation (SD), and quartiles are also reported.

When comparing prioritization practices among different 
Table 1. Examples From Guidance Document for Orthopedic Surgery and Adult Mental Healthcare

\begin{tabular}{|c|c|c|c|}
\hline Condition & Interventions & Grading According to Priority Criteria & Guidance \\
\hline $\begin{array}{l}\text { Hip arthrosis } \\
\text { - Moderate and severe }\end{array}$ & $\begin{array}{l}\text { - Drug Therapy } \\
\text { - Physiotherapy } \\
\text { - Insertion of total prosthesis }\end{array}$ & $\begin{array}{l}\text { The condition/care is considered to: } \\
\text { - Have high severity } \\
\text { - Be beneficial } \\
\text { - Be cost-effective }\end{array}$ & $\begin{array}{l}\text { - Should be assigned a right to } \\
\text { necessary care } \\
\text { - Significant ailments: Within } 12 \\
\text { weeks } \\
\text { - Moderate ailments: Within } 26 \text { weeks }\end{array}$ \\
\hline $\begin{array}{l}\text { Depression } \\
\text { - Severe to moderate } \\
\text { (MADRS score }>20 \text { ) }\end{array}$ & $\begin{array}{l}\text { - Investigation } \\
\text { - Cognitive therapy } \\
\text { - Psychoeducation } \\
\text { - Treatment with SSRI or other antidepressants }\end{array}$ & $\begin{array}{l}\text { The condition/care is considered to: } \\
\text { - Have high severity } \\
\text { - Be beneficial } \\
\text { - Be cost-effective }\end{array}$ & $\begin{array}{l}\text { - Should be assigned a right to } \\
\text { necessary care } \\
\text { - Within } 6 \text { weeks }\end{array}$ \\
\hline
\end{tabular}

Abbreviations: MADRS, Montgomery-Asberg Depression Rating Scale; SSRI, selective serotonin reuptake inhibitors.

hospitals, it may be a challenge to overcome differences in organization and structure. However, in our material all patient contacts are attributed to a coded medical specialty according to the character of the condition and the care given. For the more detailed analysis, it was necessary to select a subset of groups. We found similar patterns for different disease categories. However, the priority profiles as measured by the distribution of the guaranteed waiting times may roughly classify the specialties into three different typologies: two with distinct peaks for respectively short or long guaranteed waiting times, and the third with a more heterogeneous distribution. Nikolova et $\mathrm{al}^{14}$ also identify three sets of disease categories which are based on the difference in the magnitude of the effects, and present the results for circulatory, digestive system diseases and diseases of the nervous system. We selected four different specialties fitting the three typologies for further detailed analysis: gastroenterology, pulmonary diseases, orthopedic surgery, and mental healthcare for adults. The number of referrals for patients in these selected specialties was 73774 .

\section{Results}

The Proportion of Prioritized Patients in Different Medical Specialties

The share of referrals for patients given legal status as prioritized varies greatly by medical discipline as shown in Figure 1. For all somatic specialties the proportion of prioritized patients varied between $49 \%$ and $91 \%$. Among the psychiatric specialties and addiction medicine, a very high share of patients was assigned a legal right to specialized healthcare. Pediatric patients also range among the highest prioritized, while patients within ophthalmology, plastic surgery and general surgery range among those with the lowest priority proportion.

Prioritization Profiles - Given by Individually Assigned Maximum Waiting Times and Actual Waiting Times For the selected four specialties (orthopedic surgery, gastroenterology, pulmonary disease, and psychiatry for adults) their practice profiles for prioritized patients are given as the distribution of the assigned maximum waiting times and the actual waiting times. The results imply distinct prioritization patterns as shown in Figure 2 and Table 2. With the exception of orthopedic surgery the patterns indicate similarities in terms of left-skewed distributions for the maximum waiting times. This indicates that many referrals are given relatively short waiting times (25th percentile amounts to 30-40 days).

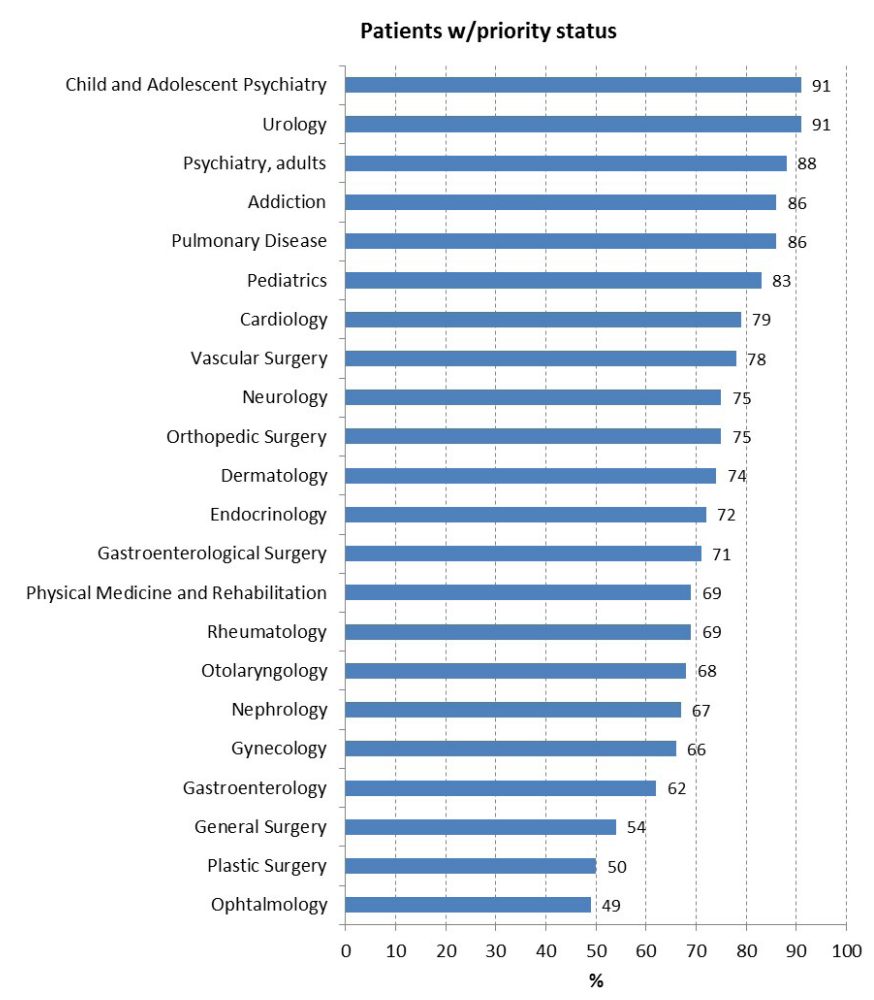

Figure 1. Proportion of Patients With Priority Status by Clinical Discipline.

The profile of maximum waiting times for orthopedic surgery is clearly different, characterized by a maximum spike at around half a year (median is 168 days). The distributions of actual waiting times vary, but one can see that they follow the profiles for the maximum waiting times relatively closely, especially for gastroenterology and pulmonary diseases. For orthopedics and mental healthcare, the two curves are clearly separate where the actual waiting times generally are reached well ahead of the maximum waiting times. The dispersion as measured by the standard deviation, are quite similar for the two waiting time measures, except for pulmonary diseases where it is higher for the actual waiting times than the maximum ones.

Planning Profiles: The Difference Between Actual Individual and Assigned Maximum Waiting Times

To visualize the planning process of the hospitals, the time interval between the maximum waiting time and the actual end of waiting time at the level of individual patients, were analyzed. A negative interval implies that care has started before the assigned maximum waiting time, while a positive 


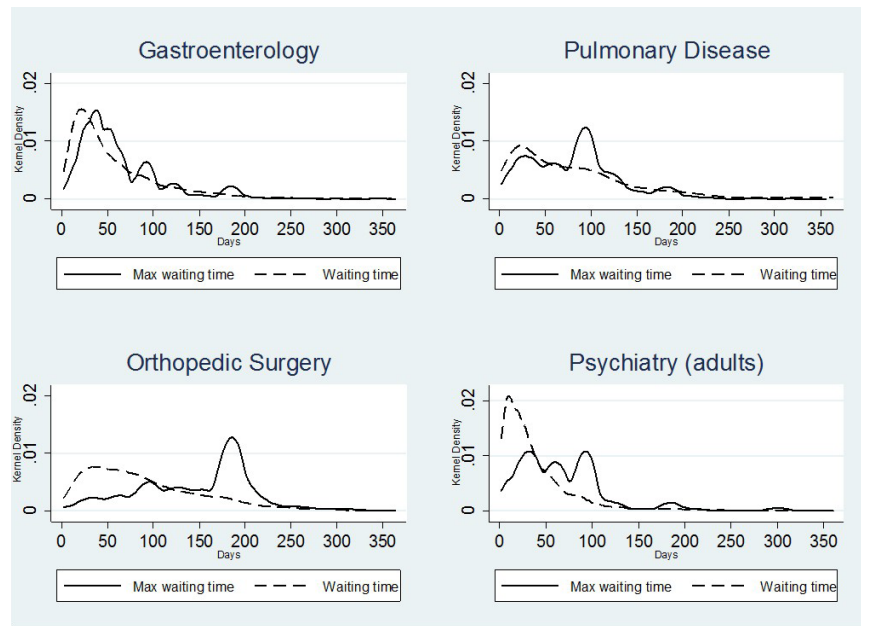

Figure 2. Maximum Assigned Waiting Time and Actual Waiting Time for Prioritized Patients in Four Clinical Specialties.

one implies that the maximum limit is violated. As Figure 3 shows, violations occur within all specialties. A common feature is that for a majority of cases, the given healthcare starts just before the maximum waiting time. And furthermore, most of the patients with violations of maximum waiting times receive care shortly after the assigned maximum limit. Apart from these common features, the profiles vary. Gastrointestinal conditions had the most prominent central tendency where on average the patients received care 7 days before the maximum waiting time, while mental health had a higher share of patients where care started (around a month) prior to the maximum waiting time. Orthopedics had the most extracted profile where the patients on average received care two months prior to the maximum time.

Priority Status Measured Alternatively According to Short or Long Actual Waiting Times

Waiting time may be considered an important indicator for real prioritization status. It is, therefore, interesting to analyze the actual waiting times independent of whether the referral was a given a legal right to priority or not. We define short waiting time as less than 30 days and long waiting time as more than 180 days. Within the selected specialties, $21 \%$ of the patients with short waiting time did not have a legal right to necessary healthcare as described above. For the ones with long waiting times, $57 \%$ of the patients were prioritized. This indicates that the degree of urgency and waiting time does not directly reflect priority group or the degree of severity. Within the selected specialties, psychiatry had the highest share of patients with short waiting times, while orthopedic surgery had the highest share of patients with long waiting times.

Discussion

In this study, we find considerable variation across clinical
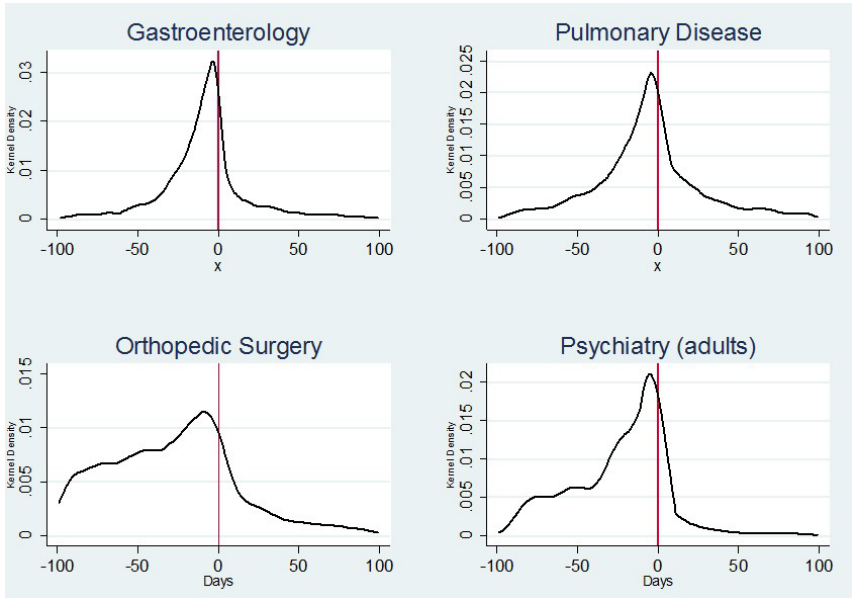

Figure 3. Interval Between Maximum Waiting Time and Actual End of Waiting Time for Prioritized Patients in Four Clinical Specialties (Distribution of Individual Patients, 2010).

disciplines in the proportion of priority patients and in their assigned individual maximum waiting times. The specialties analyzed have different characteristics and patient casemix, which are obviously reflected in the prioritization practice. Furthermore, some specialties apply only minor differentiation (most patients are assigned the same maximum waiting times, eg, orthopedics), while others differentiate more (eg, mental healthcare). The crucial point is, however, how to interpret these findings. In Norway, where the goals have been to reduce waiting time and improve fairness and equity in access, much attention has been given to variations. But very little attention is given to the question of how much variation one may expect between different specialties. As no adjustments for differences in patient severity or case-mix are applied to the results, our opinion is that quite large variation is to be expected. The national standardization processes have so far focused on standardization within specialties and not on harmonization between different specialties.

Comparisons across specialties must also take into account the heterogeneity in the extent of non-planned admissions. It is well-known that the composition of emergency versus elective patients varies considerably across disciplines. Different threshold for access to specialized healthcare is also important when interpreting results across specialties. Our assessment is based on the patients who actually received care at a hospital. A high proportion of priority patients may indicate that the threshold to get specialized healthcare is also high for these specialties. Such differences in strategies or capacity may cancel out the differences in observed actual waiting time; for example to give access to less severely ill patients compensated by longer maximum waiting times. Differences in capacity may be associated with variation in funding, ${ }^{15}$ or the prestige of different medical disciplines, ${ }^{16,17}$ but our study was not designed to explore if this was the case.

Table 2. Maximum and Actual Waiting Times for Four Medical Disciplines

\begin{tabular}{|c|c|c|c|c|c|c|c|c|c|c|c|}
\hline & \multicolumn{5}{|c|}{ Maximum Waiting Times in Days } & \multicolumn{5}{|c|}{ Actual Waiting Times in Days } & \multirow[b]{2}{*}{$\mathbf{N}$} \\
\hline & 25 perc $^{a}$ & 50 perc & 75 perc & Mean & SD & 25 perc & 50 perc & 75 perc & Mean & SD & \\
\hline Orthopedic surgery & 99 & 168 & 188 & 153 & 70 & 44 & 83 & 139 & 101 & 77 & 15.844 \\
\hline Gastroenterology & 31 & 51 & 92 & 75 & 71 & 22 & 42 & 86 & 67 & 72 & 7.907 \\
\hline Pulmonary disease & 40 & 90 & 106 & 84 & 55 & 28 & 69 & 121 & 92 & 88 & 4.750 \\
\hline Psychiatry (adults) & 37 & 64 & 92 & 75 & 53 & 19 & 36 & 66 & 51 & 55 & 4.969 \\
\hline
\end{tabular}

a Percentiles. 
The Norwegian prioritization guidance documents also allow discretion when it comes to each single patient. Based on our dataset it is not possible to evaluate whether the individual considerations and specific assessments of severity of disease, expected benefits and cost-effectiveness, were implemented equally across the specialties. Gaming the system is also possible when there is room for individual discretion.

Importantly, most of the patients received healthcare within maximum waiting times. However, we find that there are many patients receiving treatment just before the maximum waiting time. Similarly, for a large share of patients where maximum waiting time is violated, the treatment starts just after the assigned maximum waiting time. This interesting pattern indicates that the planning process itself may be a major determinant for the actual waiting time. More specifically one may hypothesize that focusing so strongly on the maximum time has led to a shift in attention and consequently unintentionally may lead to a general lengthening of waiting times. As the dispersion of the maximum times and the actual waiting times are quite similar, this may support our hypothesis. It was also supported by a pilot study from our hospital where an alternative model applying a "first come first serve" policy by simulation, resulted in generally shorter actual waiting times for the patient population. An alternative hypothesis may be that an adjustment of maximum waiting times towards the real capacity has occurred. However, in the national guiding documents, if followed, the maximum times were set according to medical criteria only. Another hypothesis could be the effect of incentives. However, the incentives in 2010 were quite weak (this was changed in 2015): there were no punishments to the hospital management and it was up to the patient to complain if waiting time exceeded the guaranteed maximum waiting time.

Another finding is the lack of correspondence between being assigned to the priority group and the actual waiting time. The fact that $21 \%$ of the patients with shortest waiting times did not belong to the priority group, and furthermore that $57 \%$ of the patients with the longest waiting times were assigned such a legal right, implies that actual waiting times do not directly reflect the relative priority given to each individual patient. An interpretation of this finding is that judgments of degree of urgency should be distinguished from judgments of degree of severity. Another explanation for this finding could be that urgency as captured by maximum waiting times is not the only factor that impact real waiting times. Drawing on the literature on demand and system capacity factors, there are reasons to hypothesize that capacity is not well-aligned with intended priorities (see for example ${ }^{2,15}$ ).

Waiting lists and prioritizations have received considerable political attention in Norway. Different policies have been implemented, both financial and judicial. In an international perspective, one can find different systems and policies introduced. However, a review of various prioritization schemes and maximum waiting time guarantees shows that the policies introduced are most effective if they are linked with economic sanctions. ${ }^{2,18}$ A comparative study that analyzed the introduced maximum waiting time targets in Norway and Scotland showed that the policy introduced in Norway in 2004, somewhat surprisingly, actually had greater impact on the patient groups with lowest priority, and that the gain was achieved at the expense of the patients with higher priority. ${ }^{19}$ Other studies - both Norwegian and international - have also found significant variations in waiting times and prioritization among different hospitals and specialties. ${ }^{19-21}$ These indicate that it is difficult to develop priority-setting mechanisms that are precise and at the same time general enough.

Other countries have introduced more formalized scoring systems for setting priorities between elective patients. One study from Canada found that the scores were most similar for surgical conditions, while there was least consensus for mental healthcare conditions. ${ }^{22}$ A Norwegian study of how health professionals would rank patients with mental health problems according to severity of the conditions, showed little inter-individual agreement. ${ }^{23}$

Our study introduces a new dimension by comparing the actual waiting times to the individually allocated maximum times. However, the results have to be interpreted with caution. There are well-known uncertainties about the quality of the register data, particularly related to differences in registration practices for setting the end-point of waiting time. According to the national regulation and guidance documents, waiting time end date must be either when the specialist starts investigation of the patient (if the condition is unclear) or when treatment is started. In practice, the end of waiting time is typically registered by the first contact at the hospital, regardless of whether investigation or treatment has actually started. This practice is also commented on in an external review. ${ }^{24}$ In addition, practices concerning registration of patients who are transferred from one hospital to another also vary.

\section{Conclusion}

Variations in prioritization practice were found across different medical specialties, both in the proportion of patients given priority status and the individually assigned maximum waiting times. We conclude that variations are to be expected, due to differences in patient case-mix and their severity of illness. Different thresholds in access to care may also contribute to the observed patterns.

One hypothesis for further research is that the introduction of maximum waiting times may have contributed to push the actual waiting time towards the maximum assigned waiting time. The finding that the start of healthcare generally was placed very close to the maximum waiting times supports this. Furthermore, there was no clear correspondence between the actual waiting times for patients and their priority status, which may imply that urgency and severity of illness are two separate entities.

\section{Acknowledgements}

This work was funded by Helse Vest (Norway's Western Regional Health Authority, Stavanger, Norway) though the project "Priority setting across clinical specialties" (Grant no: 911520). The authors also want to thank the Norwegian Patient Register (NPR) for extracting the data used in this analysis.

\section{Ethical issues}

The Norwegian Data Protection Authority, Oslo, Norway, the Regional Ethics Committee, and the Norwegian Patient Register have approved the concession 
for the use of data in this project.

Competing interests

Authors declare that they have no competing interests.

\section{Authors' contributions}

TH and OFN had the initial idea, with input from JJG. TH and JJG led the analyses and all three authors drafted the text and subsequently read, revised, and approved the report. OFN had final responsibility for submitting for publication.

\section{Authors' affiliations}

${ }^{1}$ Department of Finance, Haukeland University Hospital, Bergen, Norway. 'Department of Research and Development, Haukeland University Hospital, Bergen, Norway.

\section{References}

1. Ringard A, Sagan A, Saunes I, Lindahl A. Norway. Health system review. Health Syst Transit. 2013;15(8):1-162.

2. Siciliani L, Borowitz M, Moran V. Waiting Time Policies in the Health Sector: What Works? OECD Publishing; 2013.

3. NICE Pathways. http://pathways.nice.org.uk/pathways/serviceuser-experience-in-adult-mental-health-services. Accessed October 30, 2015.

4. Norges Offentlige Utredninger. Guidelines for Priority Setting in the Norwegian Health Care System [Norwegian]. Oslo: Universitetsforlaget; 1987:23.

5. Norges Offentlige Utredninger. Priority Setting Revisited [Norwegian]. Oslo: Statens forvaltningstjeneste, Statens trykking; 1997:18.

6. Helse- og omsorgsdepartementet. Lov om pasientrettigheter. LOV_1999-07-02-63; 1999.

7. Sosial- og helsedirektoratet. Prosjektdirektiv for Samarbeidsprosjektet Riktigere prioritering i spesialisthelsetjenesten; 2006.

8. Helsedirektoratet. Ventetid og pasientrettigheter, IS-8/2009. Oslo: Helsedirektoratet; 2008.

9. Helsedirektoratet. Ventetider og pasientrettigheter. https:// helsedirektoratet.no/Lists/Publikasjoner/Attachments/532/ Ventetider-og-pasientrettigheter-2010-IS-1895.pdf. Published 2010.

10. Norheim O. Praktisering av prioriteringsforskriften i Helse Vest. Sluttrapport. Bergen: Helse Vest; 2005.

11. Sosial og helsedepartementet. St.meld. nr. 26 (1999-2000) Om verdiar for den norske helsetenesta. Oslo; 1999.
12. Helsedirektoratet. Prioriteringsveiledere. http://helsedirektoratet. no/publikasjoner/Sider/default.aspx?Kategori=Veiledere\&Tema $=$ Kvalitet+og + planlegging\&undertema=Prioriteringer. Published 2009.

13. Cameron A, Trivedi P. Microeconometrics: Methods and Applications. Cambridge: Cambridge University Press; 2005.

14. Nikolova A, Sinko A, Sutton M. Do maximum waiting times guarantees change clinical priorities for elective treatment? Evidence from Scotland. J Health Econ. 2015;41:72-88.

15. Worthington DJ. Queueing models for hospital waiting lists. $J$ Oper Res Soc. 1987;35(5):413-422.

16. Norredam M, Album D. Prestige and its significance for medical specialities and diseases. Scand J Public Health. 2007;35(6):655-661.

17. Album D. Sykdommers og medisinske spesialiteters prestisje. Tidsskr Nor Laegeforen. 1991;111(17):2127-2133.

18. Propper C, Sutton M, Whitnall C, Windmeijer F. Did "targets and terror" reduce waiting times in england for hospital care? Journal of Economic Analysis \& Policy. 2008;8(2).

19. Januleviciute J, Askildsen J, Holmås T. The impact of different prioritisation policies on waiting times: case studies of Norway and Scotland. Soc Sci Med. 2013;97:1-6. doi:10.1016/j. socscimed.2013.07.010

20. Askildsen J, Holmås T, Kaarboe O. Monitoring prioritisation in a public health care sector. The case of Norway. Health Econ. 2011;20(8):958-970. doi:10.1002/hec.1659

21. Dimakou S, David P, Devlin N, Appleby J. Identifying the impact of government targets on waiting times in the NHS. Health Care Manag Sci. 2009;12(1):1-10.

22. Noseworthy T, McGurran J, Hadorn D. Noseworthy TW, McGurran JJ, Hadorn, DC. Waiting for scheduled services in Canada: development of priority-setting scoring systems. J Eval Clinic Pract. 2003;9(1):23-31.

23. Holman P, Ruud T, Grepperud S. Horizontal equity and mental health care: a study of priority ratings by clinicians and teams at outpatient clinics. BMC Health Serv Res. 2012;12:162-166. doi:10.1186/1472-6963-12-162

24. Riksrevisjonen. Riksrevisjonens kontroll med forvaltningen av statlige selskaper for 2011. Del III - Resultater av utvidede kontroller. Sak 1: De regionale helseforetakenes registrering, resultatrapportering og måloppnåelse for ventetider. Dokument 3:2, 2012-2013. https://www.riksrevisjonen.no/rapporter/ Documents/2012-2013/Dokumentbase_3_2_2012_2013.pdf. Published 2012. 